\title{
Sustainability by Interrelating Science, Society and Economy in Embedded Political Economy - an Epistemological Approach
}

\author{
Masudul Alam Choudhury ${ }^{1}$ and Lubna Sarwath Mohammad ${ }^{2}$ \\ ${ }^{1}$ College of Commerce and Economics, Sultan Qaboos University, Muscat, \\ Sultanate of Oman and International Chair, Postgraduate Program \\ in Islamic Economics and Finance, Trisakti University, Jakarta, \\ ${ }^{2}$ Faculty of Economics (Islamic Economics and Finance), Trisakti University, Jakarta, \\ Indonesia
}

\section{Introduction}

Sustainability is a far wider concept than in the environment context. Besides, when ecology is invoked to establish sustainability the concept assumes a wider field of ethical and social evaluation. Such an evaluative domain involves embedding among a wide field of interactive subsystems. The systems learn by synergy and unify in the midst of the good things of life. The learning and choice of the good things of life through the interactive systemic synergy conveys the essential meaning of ethicality. Systemic learning as an embedded phenomenon in a unification framework of human ecological setting establishes the substantive meaning of sustainability (Hawley, 1986). Indeed, the South Commission (1990, p.13) defines development as such an embedded process in the following words: "To sum up: development is a process of self-reliant growth, achieved through participation of the people acting in their own interests as they see them, and under their own control."

Yet the context of learning by synergy is not prevalent in this definition of development. The process of choice by participating individuals in the light of their own interests could very well be a ruthless experience in competition and self-interest -- if not of individuals then of collusive groups. In the sustainability debate we find such a conflict to be entrenched. Consider the conflict between global corporation and small enterprises. One complains of the other for their individual impediments to growth (Barbier, 1986). Yet it is a fact that enterprises must necessarily survive within the reality of markets, an institutional regulatory framework, and participatory mechanism (Kim \& Mauborgne, 2005). Besides, there is also the conflict between the present and future generations, whereby the magnitude of financial and physical resource allocation problem between the present and future generations remains indeterminate. The savings problem is unresolved in the intertemporal case (Phelps, 1989).

In fact, there is no participation between the present and far future generation. These two are not contiguous, and hence cannot co-determine, participate and interrelate. Thereby, there does not exist a discounting for such indeterminate future preferences and the resource allocation linked with such out-of-bound resource allocation points beyond 
overlapping generations (Choudhury, 2011). Consequently, the expressed ethical problem of intertemporal resource allocation to maximize the associated discounted utilities of future non-overlapping generations fails in the methodological problem of valuation of a resource bundle. Only the mystical shade of ethical feeling at the cost of ethical reality prevails (Inglott, 1990). Neither the South Commission Report nor the Brundtland Report on sustainable development addresses the intergenerational ethical problem of resource allocation even though a certain form of collusive participation involving community, national and social collusion, namely between the North and the South, is emphasized. Globalization as a result assumes the façade of conflict and individuating transnational cultural identities (Sklair, 2002).

The theme of sustainability invoked in this paper is premised on the episteme of unity of knowledge and its impact on unified social reconstruction. This approach involves a substantive methodology and a specific perspective of application. The research investigation in the epistemological basis of sustainability by synergistic learning process involves an endogenous ethical symbiosis. It is extensively embedded in ever-expanding domains of social activities for the common good of all. We explain below the underlying methodology as such a complex learning process.

\section{Objective}

Three principal undertakings comprise the objective of this paper. Firstly, we will establish the epistemic methodological formal expression for the model of unity of knowledge and the sustainability criterion under the emergent symbiotic system perspective. The internal dynamics of the inter-systemic embedded domains in the study of sustainability with endogenous ethical dynamics between science and society including the global economic order will be explained in the context of political economy. The idea of political economy in this context will be explained in terms of the epistemic dynamics of unity of knowledge and its symbiotic process of systemic learning between social and scientific, hence socio-scientific, diversity. Secondly, the emergent methodological formalism of sustainability will be contrasted with other ones of similar types in received literature. This is a deeply epistemological issue on the theme of selecting the correct premise for unity of knowledge, thereby defining the unified world-system as a social construction enabled by invoking the episteme of unity of knowledge. Thirdly, we will apply the emergent sustainability worldview to the institutional political economy of the Copenhagen Summit on Climatic Change.

\section{Explanation of key concepts as the building blocs of the learning model of sustainability in this paper}

This section defines and explains some key terms and concepts that are to be used in the construction of the generalized system model of unity of knowledge as the episteme and its application to the theme of sustainability.

\section{Sustainability}

In mainstream literature of economic development, sustainability is defined as the growth and progress of the economy in keeping with non-inflationary economic advancement in real output. Economic development is also construed as the conveying of the fruits of such growth for the benefit of labor and enterprise big and small, and the attainment of environmental preservation and social justice derived from the consumption, production and distribution of goods and services to all of the present and future generations. 
In this paper, sustainability is the entirety mentioned above. But the attainment of such a compendium of wellbeing is not taken in the sense of economic optimization of these possibilities. Rather, the paper addresses sustainability as learning process established by organic complementary interrelations between the good things of life. Indeed, such an idea of complementarities out of choices of the good things of life is the meaning of wellbeing. We will expand on this idea below.

\section{Ethics}

In received literature ethics is understood as humanly driven behavior to attain utilitarian objectives that may be collectively derived though they exist as individual objectives. The foundation of such an understanding of ethics is the rational process that emanates distantly in the metaphysical moral law, but is utterly changed to assume a humanistic character.

In this paper, the meaning of ethics is equivalent to the learning process premised on the evaluation of an existing degree of unity of knowledge in the examined system of sustainability. This is then followed by the formalism of social reconstruction to gain the state of complementarities between the variables representing the good things of life. These bundles of variables as vectors are like Rawls' primaries (Rawls, 1971). Thus the following chain of relations prevails in the understanding of ethics in the context of our explanation of sustainability:

$\begin{array}{llll}\begin{array}{l}\text { Episteme of } \\ \text { Unity of knowledge }\end{array} & \begin{array}{l}\text { learning process } \\ \text { in unity of knowledge } \\ \text { and its evaluation and } \\ \text { construction of the } \\ \text { world-system }\end{array} & \begin{array}{l}\text { evaluation of } \\ \text { the problem of } \\ \text { the world-system: } \\ \text { estimating existing } \\ \text { state followed by } \\ \text { social reconstruction }\end{array} & \begin{array}{l}\text { simulation } \\ \text { of the } \\ \text { wellbeing } \\ \text { objective } \\ \text { criterion }\end{array} \\ & & \begin{array}{l}\text { In given learning process } \\ \text { the ethical consuence }\end{array} & \begin{array}{l}\text { continuity across } \\ \text { continum of } \\ \text { knowledge, time } \\ \text { and space } \\ \text { dimension } \\ \text { (Choudhury, 2009a) }\end{array} \\ & & \end{array}$

The meaning of ethics so understood is similar to how Nozick (2001) explains ethics in his following words (p. 240):

Our actions are mutually connected when my actions are connected with yours and yours with mine. Frequently, the actions of different people are mutually connected and the outcomes are nontrivially affected. This is the background that gives rise to ethics.

\section{Episteme}

We adopt the meaning of episteme given by Foucault (trans. Scheffler, 1972, p. 191) as follows:

By episteme we mean the total set of relations that unite, at a given period, the discursive practices that give rise to epistemological figures, sciences, and possibly formalized systems The episteme is not a form of knowledge (connaissance) or type of rationality which, crossing the boundaries of the most varied sciences, manifests the sovereign unity of a subject, a spirit, or a period; it is the totality of relations that can be discovered, for a given period, between the sciences when one analyses them at the level of discursive regularities. 
In a like sense of the concept of episteme in this paper, we mean by episteme the totality of the ontological and phenomenological precept and formalism premised on the epistemology of unity of knowledge. This primal concept is followed by its inductive capability out of the deductive premise. This primal precept of unity of knowledge denotes the episteme. It is subsequently followed by the entire system of learning experiences in evolving processes of unity of knowledge. The episteme of unity thereby induces the variables and entities of sustainability.

\section{Functional ontology and epistemology}

Ontology according to Heidegger (trans. Hofstadter, 1988, p. 128; Kant, ) is encapsulated in this passage:

Transcendental knowledge relates not to objects, not to beings, but to the concepts that determine the being of beings. 'A system of such concepts would be called transcendental philosophy.' Transcendental philosophy denotes nothing but ontology.

Yet in our paper ontology assumes a functional, i.e. an engineering meaning (Gruber, 1993). In this perspective, the universe assumes a mathematical form in which symbolization acts as reflective soul of reality of specific issues and problems, of the nature of the universe that we want to study as a world-system. The universe and sustainability as continuous learning by epistemic unity in it across 'everything' (Barrow, 1991) is a mathematical semiosis (Heiskala, 2003) of the socio-scientific order. Thus we will use the meaning of functional ontology as opposed to the metaphysical conception of ontology to mean the formalism of a specific idea. This is the being of becoming of an idea, which means (functional) ontology in this paper.

According to the functional meaning of ontology, the theory of knowledge (epistemology) and the ontological principle are made up of two parts that encircle and evolve in the continuum of knowledge, time, space dimension. These two parts are firstly, the epistemic derivation of unity of knowledge from a primal premise. Secondly, such an epistemic knowledge flow develops the concrescence (Whitehead, trans. Griffin \& Sherburne, 1978, pp. 20-30) of the world-system of unified forms representing the ontological formalism of the socio-scientific order. Sustainability as explained earlier in the domain of organic complementarities (i.e. participation $=$ organic unity) res extensa is the cause and effect circularity of the above-mentioned two parts across continuum of systems and over time.

In light of the above definition and explanation of ontology and the ontological principle of being and becoming, epistemology, the theory of knowledge, and ontology as theory of functional forms as description of the dynamics of being and becoming of the socio-scientific universe - its semiosis -- are juxtaposed. Episteme as totality of the phenomenological content of meaning emerges from epistemology (idea) and leads to functional ontology; and ('and' -- this meaning here is taken in the sense of mathematical intersection) ontology leads into evolutionary epistemology across continuum of systems and knowledge, time and space dimension. Such is the consequential vintage of sustainability. See below for further explanation on this dynamics of creativity.

Socio-scientific world-system

The epistemological-ontological delineation of the model emergent from expression (1) is of the universal and unique type in respect of its possibility for explanation and application to the widest possible domain of systems, issues, and problems res extensa. (Descartes, trans. Commins \& Linscott, 1954, p. 176). Hence, despite the diversity of problems addressed for systems under consideration, the meta-model of epistemic unity and sustainability remains 
invariant. That is because the primal cause, the consequential effect, and the recursive and evolutionary continuity of the same relations are uniquely premised on knowledge simultaneously with its induction of variables, entities and events. The totality of such diversity of systems and events by knowledge induction of a unified order is the idea of the unified world-system. The fact that such unifying systems span across all domains -- the meaning of universality by virtue of the epistemic role of unity of knowledge -- causes science, ecology, society and economy to interact, integrate and evolve by organic symbiosis. The resulting embedding domain is the wider field of social valuation comprising our scope of political economy.

\section{Political economy}

Political economy is a discipline of thought -- but not the pedagogical study -- of power and conflict in states of production, ownership and distribution. These activities together assume a meaning of systemic concrescence in embedding political economy. The domains of science, society and economy are now integrated together out of systemic interaction and the learning spaces of evolutionary epistemological dynamics.

Staniland (1985, p. 33) invokes reference to Lionel Robbins on the concern with the scientific (epistemological) as opposed to the institutional (pedagogical) approach to the definition of political economy in the following words: "Lionel Robbins acknowledged that the logical basis of welfare economics was flawed, that it was impossible to arrive at a scientific definition of the general good from an examination of individual preferences. But governments had to make judgments about such matters, and values were inescapably involved in such judgments. Therefore Robbins proposed dividing the field into 'political economy', which dealt with such important but essentially unscientific matters, and 'economic science', which would continue the central, normatively neutral tasks of analyzing the facts of economic behavior"

The understanding and application of the theme of political economy are different in this paper. We define political economy in the scientific framework of interaction, integration and evolutionary epistemology of unity of knowledge caused by the convergence to unification of 'everything' according to the methodology of learning processes res extensa differentiating truth and falsehood. The scientific universality and uniqueness of this methodology are preserved while bringing together what in the above quote means unscientific institutionalism. Scientific formalism of the meaning of institutionalism is fired by its own dynamics of preferences, structures and creative futures. The resulting symbiotic worldview is the essential characteristic of our definition of political economy. Within such a worldview is subsumed the opposing study of conflict and cooperation on the theme of production, consumption, ownership and distribution of wealth and resources, and all the opportunities that emerge there from.

On such a systemic spanning perspective of the field of political economy the organic model of interrelationship between epistemology and development (Koizumi, 1993) can be adopted to explain our systemic and unification concept of political economy. It integrates 'everything' within a modeled framework of human reality partitioned between truth and choices of the good things of life on the one side; and falsehood and differentiation of life on the other side.

\section{Evolutionary learning process}

The meaning of process in the sense of the ontological principle rests on the principle of being and becoming (Prigogine, 1980). Process breeds sustainability by virtue of the unified 
nexus of organic relations between diversity. This idea of sustainability and learning process is represented in expression (1). In this regard, Whitehead (op cit, p. 80) writes: "The philosophy of organism extends the Cartesian subjectivism by affirming the 'ontological principle' and by contrasting it as the definition of 'actuality'. This amounts to the assumption that each actual entity is a locus for the universe."

The consequence interrelating epistemology and functional ontology along the reproduction of knowledge and its constructed world-system of unity of knowledge is the essential meaning of learning. Sustainability is borne by and of itself in continuum of the knowledge, time, and space dimension. The universe takes its form and reshaping in such a continuity and systemic continuum of organic forms and their inter-relations.

To configure the study of the learning process and the forms of sustainability and ethics embedded in it this paper brings out definitive functions inherent in the meaning of evolutionary epistemology. The idea is emphatically explained by Campbell (1974, pp. 413463): "The central requirement becomes an epistemology capable of handling expansions of knowledge, breakouts from the limits of prior wisdom, scientific discovery." In our paper such a permanent characteristic of learning process assumes a universal and unique socioscientific construction.

\section{Interaction}

Interactions arise from the diversity of organic relations and their immanent forms that agencies, entities, variables and their relations assume in the study of specific problems, subject to pervasive inter-organic complementarities. Imbuing interactions with their legitimacy emanates from the epistemic foundation of unity of knowledge, whereby the immanent organisms - human and non-human ones - are construed as being pairs of complements. Yet the idea of pairing is one of unity between the good things of life. Oppositely, pairing in modes of competition is the permanent characteristic of the domain of organic competition. Thus a logical contradiction arises from the former kind of unified worldview and the latter kind of social Darwinism (Darwin, 1985, p. 115).

The meaning of interaction in the sense of sustainability by virtue of the learning process means the initial recognition of the legitimacy of paired complementarities as the sure sign of unity of knowledge that is embedded in the systemic domains of diversity. In the social Darwinian sense the contradictory explanation of interaction is worded as Natural Selection by way of competition, marginalism, and association among similar organisms that compete to dominate.

\section{Integration}

Integration necessarily breeds as the consequence of interaction. Integration is the processdetermined stage of realized unity of being out of its becoming through the interactive process. Integration marks order out of diversity of interactions that search for symbiosis. Integration follows interactions because only discursive, relational and divergent learning situations can yield to consensual order in the socio-scientific domain, and similarly to symbiosis in the inanimate domain of 'everything'. Any consensus that precedes interactions conveys a denial of freedom of participation. Participation is essential in forming a unified world-system by the episteme of unity of knowledge.

How does integration arise out of a system of interaction? In the social domain the bundle of interactions denote possibilities of unity of knowledge in respect of particular issues that altogether interrelate to unify together in forming a mapping of the possibilities onto the 
unified ensemble (Hubner, 1985). In the physical domain, biological diversities unify together to form unified bundles of types conforming to specific categories. But central to such interaction leading to integration is the fact that knowledge remains the be-all and endall of the unification process, and hence of the learning process defining sustainability across the knowledge, time and space dimension of reality.

Consequently, inter-systemic diversity is able to unify in the knowledge-relational sense to form the organizational structure of the diverse entities that now become unified -- not by forms in the primal, but by the basis of knowledge. Two examples are given here:

The unification of the North and South geopolitical world-systems into a unified world order is the good form of globalization (Behrman, 2003). So-called Darwinian biological primates converge with human beings in terms of the knowledge organization to share coexistence of the planet earth. Such a process is different from the type of social Darwinism of the selfish gene (Dawkin, 1976).

The above-mentioned are examples of sustainability reflected in entities, but not by the evolution of species by way of competition and replacement of survival of the fittest. Sustainability here means the knowledge that enables coexistence to participate and to share in the resources of the planet earth.

The principle of pervasive complementarities is thereby the simulated normative consequence of improving on all relations of the positivistic nature, either of competition or coexistence. The endemic social reconstruction in the transformation of unwanted positivistic situations into simulated normative possibilities of complementarities, hence unity of being, is a function of knowledge. The episteme of unity of knowledge establishes the functional ontology of knowledge through the social derivation of knowledge flows. These knowledge-flows form the laws and preferences of the socio-scientific order at large. The consequential representations of the resulting world-system are thus knowledgeinduced. These induced entities and relations are now capable of learning further on, as explained by expression (1). The result is generating sustainability across continuous learning processes in knowledge, time, and space dimension.

\section{Evolution}

Evolution is a function of knowledge-flows causing the bursting of new knowledge-flows from the previously attained ones through the process of learning in unity of knowledge across specific experiences. Such experiences occur at specific points of the knowledge, time and space dimension. Evolutionary epistemology arising from the sequential process of interaction leading to integration is thereby continuous across continuum of knowledge, time and space dimension.

We need to ask how evolution arises from (interaction to integration) and cannot arise in any other juxtaposition. In the knowledge, time and space dimension of the learning worldsystem, knowledge precedes the occurrence of event. Hence knowledge in its foundational epistemic stage, subsequently followed by the simulation of derived knowledge-flows by means of the discursive mechanism, is firstly a spatial experience. It is then followed by its evolutionary continuity over time.

The knowledge-formation stage of the learning continuum, hence evolutionary epistemology in the continuum of space at a point of time marks the interaction-integration dynamics. This stage of knowledge formation and the simulation process at a given point of time thus establishes the continuum phenomenology (knowledge-induced transformation at a point of time). Next the interaction-integration continuum of phenomenology is protracted over time. 
Sustainability thereafter continues by the joint protraction of (interaction-integration) over time, forming thus the logical and cognitive forms across continuums of timal continuity. This phase of continued learning marks emergence of domains of evolutionary epistemology in the res extensa of systems, entities, variables and relations. On such a coevolutionary phenomenological experience in continuum and over time, namely, the representation of the total dynamics over knowledge, time and space dimension pertaining to the episteme of unity of knowledge and its unification relationship with the world-system writes Primavesi (2000, p. 110): “... the evolutionary possibility of our interacting peacefully, fruitfully and happily with other organisms cannot be ruled out".

The feature of continuous and discrete timal coevolutionary learning processes is found in Nozick's argumentation (2001, p. 43). But we remove the relativism of truth in Nozick by the permanence of truth existing as exogenous foundation outside time-space, though truth de facto relates with time-space events to actualize evolutionary epistemology and forms of the world-system. In our terms therefore, truth as knowledge of the foundational episteme is not relativistic. It is the cement in the overarching totality between the derived and discoursed knowledge-flows and the unifying world-system actualized out of social transformation.

Thus epistemic knowledge is the exogenous factor of cause in space-time dimension of the world-system. This is the fundamental origin of sustainability. Without this strong implication we disagree with Nozick who says, "Our theory places truth within space-time". Obviously, the meaning of epistemic knowledge is different between the relativistic knowledge, which to us means temporal knowledge-flows. But such knowledge-flows are foundationally derived by the combination of absolutist truth based on text and history of the good things of life, and the discourse of the enlightened society. Braudel (1995) referred to this kind of worldview as the consciousness of history of the long dure. Now in regards to expression (1), sustainability takes a multidimensional meaning. It involves in it res extensa the socially converged structures of science, society, and economy; hence of the embedding political economy as the coordinated unified, interactive, integrative and evolutionary system that we have pronounced.

In the coevolutionary phase of the learning process there is no binding prediction for the evolutionary processes to be definitely truth-knowledge directed. It is possible that contradictory scenarios of evolutionary epistemology can emerge and continue, or they can revert again to the socially constructed path of change. An example is that of the absolutist episteme of unity of knowledge (truth) disintegrating into Darwinian evolutionary processes (Popper, 1988), and then again reverting to the autopoiesis of Gaia, which refers to "the dynamics, self-producing and self-maintaining network of production processes within live organisms" (Primavesi, p. 2).

A note needs to be made on the nature of absolutism contra relativism in the truth-knowledge amalgam. Unlike the many speculative philosophers of all times, in our paper there is no relativism of truth and the epistemic knowledge. We make the argument that, if this was the case then the world and reality would descend into an endless spiral of void and nothingness. There is no basis; everything remains relative, changeable, and hence unfounded. Now to emanate two streams of truths from disparate epistemic origins means the reign of perpetual competition, marginalism and differentiation of existence. In this kind of reality there cannot prevail coexistence, coordination, unity and sustainability. Unfortunately, such a competing and marginalizing dichotomous worldview is the basis of all of western science of nature and society. The resulting political economy then is seen as the study of conflict and competition 
between unsustainable opposed groups that oppositely claim power over the production, consumption, distribution and ownership of wealth.

Contrary to the idea of relativism of truth, the absolutism of the unitary episteme means irreducibility of certain laws and the socio-scientific implements derived there from by a regressive method of argumentation and belief. Such a truth that is solely premised on the episteme and functional nature of the precept of oneness is absolutely inexorable, implacable. Socio-scientific sustainability now becomes uniquely and universally attainable by means of the extension of unity across nexus of cohering systems res extensa.

In the end, there is no relativism of truth. At the epistemic level the identity of topological mappings causes Truth $\equiv>$ Epistemic Knowledge of Oneness $\equiv>$ Truth, in the sense of equivalence of relations denoted by $\equiv>.1$

Wellbeing

Unlike utility and welfare functions, which are neoclassical concepts of optimum economic objective criteria for the individual and household, and community and government,

\footnotetext{
${ }^{1}$ If possible, let $\Omega_{1}$ and $\Omega_{2}$ be two origins of relative truths, if possible. Then $\Omega_{1} \cap \Omega_{2}=\phi$. Consequently, by the topological property of each and all the mappings (Maddox, 1970), $\left\{\mathrm{f}_{\mathrm{i}}\right\}, \mathrm{i}=1,2, . ., \mathrm{n}$; the domains of these mappings denoted by $\left\{x_{s}\right\} \cap\left(x_{q}\right\}=\phi$, plus their functional relations taken in bundles have the property, $\left\{\mathrm{f}_{\mathrm{p}}\left(\mathrm{x}_{\mathrm{s}}\right)\right\} \cap\left(\mathrm{f}_{\mathrm{r}}\left(\mathrm{x}_{\mathrm{q}}\right)\right\}=\phi$; with $\mathrm{i}, \mathrm{p}, \mathrm{q}, \mathrm{r}, \mathrm{s}$ with assigned numbering either over finite, infinite, discrete or real sets. Hence truths and their consequences over entities, variables, relations and domains remain differentiated. No interaction is possible. Hence integration through the interactive learning process and evolutionary epistemology is impossible. Consequently, ethics and causal interrelationships remain impossible. There is no embedding as of science, society and economy within political economy. Sustainability is permanently denied to such a differentiated system.

Contrarily, if $\Omega_{1}$ and $\Omega_{2}$ are relational, then say, $\Omega_{1} \cap \Omega_{2} \subset \Omega \neq \phi$. In the denumerable case of all numbered topological mappings of variables as mentioned above, it is possible to find an associated non-zero and non-identity scalar factor $\alpha$, such that $\Omega_{1} \bullet \Omega_{2}=\alpha$.I $\subset \Omega \neq \phi$, with I as the identity set. Consequently, $\Omega_{1}$ and $\Omega_{2}$ are only near relational inverses of each other with a convergence towards $\Omega$, but with an $\alpha$-scalar margin of identity.

The conclusion is that with $\Omega_{1}$ and $\Omega_{2}$ as disparate knowledge, both of them are encompassed by the law (topology) of $\Omega$. Therefore, $\Omega \equiv$ Truth. Besides, Truth is epistemic Knowledge because it has functional essence displayed by the topological mappings emanating from $\Omega$ and routing through $\Omega_{1}$ and $\Omega_{2}$. Thus, $\Omega \supseteq$ Truth $\equiv$ Knowledge. But Truth $\equiv$ Knowledge $\subseteq \Omega$. Thereby $\Omega \leftrightarrow \Omega$. Hence, $\Omega$ selfreferences. Likewise, the epistemic Truth $\equiv$ Knowledge self-references (Choudhury \& Zaman, 2009). This is the temporal consequence of sustainability as the learning process over continuum and in continuity of the knowledge, time and space dimension. The topological subsets in this sustainability concept is the embedding of science, society, economy in political economy with its relational power of ethicality gained by learning, i.e. interaction, integration and coevolutionary epistemic unity.

The special case is that of the metaphysical ontology of 'being' in unity as Truth equivalent to Knowledge, when $\alpha=0$. That is error in relative relationalism is zero. Then $\Omega_{1} \cap \Omega_{2}=\phi$. We now term $\Omega_{1}$ and $\Omega_{2}$ as Truth and Falsehood, respectively. Thereby, Truth and Falsehood or Relative Truths become perfectly disjoint.

In the end altogether, sustainability is attainable at a margin of deflection (error) in our mundane experience; sustainability as the perfection of Truth and Knowledge in the epistemic sense remains optimally attained. Consequently, the world-system established on the basis of the epistemic unity of being and becoming does not stand on the relativity of truth. In the mundane sense only, as in the case of science, society, economy embedding in political economy, evolutionary knowledge is simulated by discursive learning on the premise of the epistemic unity and its unified social reconstructions.
} 
wellbeing is a simulative objective criterion function. It conceptualizes and measures the degree to which organic complementarities, reflecting unity of knowledge in the systemic organic relations between the good things exist, or simulative social reconstructions can be improvised.

The social welfare function of welfare economics is defined as a mathematical mapping from the domain of socially selected states to their outcome in the social space. Such a functional map has the following mathematical properties to make it viable for analytical work (Quirk and Saposnik, 1968, pp. 105-108): Social choices comprise vector-bundles $X_{1}$ and $X_{2}$, such that either $X_{1}$ is preferred to $X_{2}$ or vice-versa, or these are indifferent to one another at the individual level. These directions of social choices at the individual level are mapped on to the social level while the axioms of economic rationality are preserved. That is preferences remain unchanged along the mapping from the individual to the social level. Transitivity of preferences over bundles of goods (variables) in rational choice at the individual level is preserved at the social level as well.

Social welfare function involving the preservation of the properties of the mapping from the individual to the social level needs a dictator to impose attainment of social welfare level by a given set of social choices. Irrelevant preferences hold for a subset of society, where a truncated form of the welfare function can be extended to the whole of society (Hammond, 1987). It is equally possible to replicate the social welfare function in terms of bundles of social choices, e.g. economic growth, distributive justice, employment and price stability, or in terms of individual utility functions in terms of these variables individually chosen. They are then aggregated socially.

Thus, the principal rationality property of individual utility function and its effect on private choices to make up aggregated order-preserving social choices, namely by means of the postulate of marginal substitution and exogenous preferences and ethical implication, remain in tact both at the individual and social levels. This is the idea of pervasive substitution and marginalism, scarcity of resources, economic rationality in choices, nondynamic preferences and full information (or bounded rationality as in Simon (1957)). Consequently, the idea of sustainability in the sense of social embedding of interacting, integrating and creatively evolutionary systems is never prevalent in mainstream conception and applications of science, society and economics.

On the other hand, wellbeing function is a mapping from the social space of states with endogenous ethical induction of the variables on to the space of social outcome as measured by the degree of complementarities between the social choices of the good things of life as they are represented in the social variables with ethical induction. In the social wellbeing space ethics is parametrically estimable for which simulation possibilities exist to arrive at better social reconstructions.

A social wellbeing function does not stand alone. It is there for purposes of evaluation of the prevalent state that can lead into simulated states of social reconstruction. Hence the social wellbeing function is estimated and simulated with respect to a system of circular causation interrelations between the variables, all of which are endogenously ethically induced.

There is no substitution between the variables and functional inputs (e.g. consumer utility indexes) in the wellbeing function, as it is otherwise found in the case of the welfare function. The implication of these two properties is this: There is permanent substitution between social choices in the welfare function; and pervasive complementarities or social reconstruction of social choices in the wellbeing function. Sustainability explained by the embedding of science, society and economy in the social political economy by way of 
continuous learning process in unity of knowledge as the episteme is never a possibility in the order of substitution between possibilities. Possibilities are always to be complemented for augmenting knowledge-flows and their material inductions as ethically-induced resources for human development and reproduction of resources, rather all kinds of resources for life-sustenance.

With the continuous augmentation of resource as the result of the growth of knowledgeflows and their induction of social variables into evolutionary discovery of possibilities, the contrary core postulate of scarcity in received economic theory, or Darwinian conception of biology and anthropology, and optimization concepts of scientific theories are all replaced by the theory of coevolutionary symbiosis. A theory for this kind of dynamics is uniquely and universally explained by the Interaction-Integration-Evolutionary (IIE) phases of the learning processes, as explained earlier.

While the problem of sustainability is seen in the eyes of scarcity in the case of mainstream common understanding by science, society and economics (Coombs, 1990; Martinez-Alier, 1987), scarcity is abandoned in a logical way in the sustainability concept of complementary learning processes (Daly et al, 1992). The postulate of diminishing marginal returns to scale of received economic and social theory does not exist in the knowledge-induced learning space and its model of organic unity of knowledge (Romer, 1986). Yet coexistence is the possibility, unlike the evolutionary process models of Darwinian type of social choice (Myrdal, 1987) and science (Hull, 1988).

Indeed, knowledge for participation and sharing is power. When knowledge-flows continue under this epistemic framework of induced possibilities, the latter artifacts become the bastion of rediscovered resources ad-infinitum. Now the wellbeing function becomes exclusively an objective criterion of learning processes and interactive-integrativeevolutionary (IIE) systems premised on epistemic unity of knowledge.

Therefore, pervasive complementarities are inherent in the systemic interrelations between the variables chosen to describe the wellbeing function. The feedback relations that emanate from the estimation followed by the simulation of the wellbeing function in terms of the interrelations between the variables that are pervasively complementary to each other form a system of circular causation relations.

The system of circular causation relations are used for dual purpose. Firstly, they are estimated by using positivistic data from the 'as is' state of the sustainability problem under examination. The unity dynamics of being and becoming towards attaining a semblance of social reconstruction of a unified world-system requires coefficients to be simulated into better values to exhibit inter-variable complementarities. This simulated change in the coefficients convey the idea of social reconstruction or social simulation from a positivistic order of 'as is' reality into a normative aspired transformation for an 'ought-to-be' better world of sustainability. The latter world-system is gained by unity of knowledge induced in its unity of the problem under study. In such a context, the social political economy takes its meaning of embedding between the synergies of science, society and economy (Choudhury, 2003 , 2007). The conformable meanings of systemic globalism and globalization follow. See later.

\section{Social (re-) construction}

The empirical and applied part of the theory of unity of knowledge on the issues and problems of the world-system res extensa is established by the estimation followed by simulation of the wellbeing function, subject to the system of circular causation relations. 
Social Wellbeing Function (SWBF)

Subject to circular causation relations

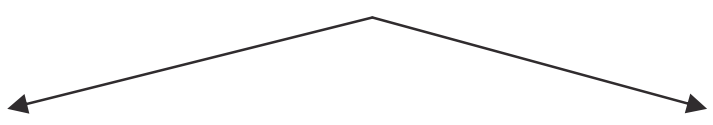

Estimation of SWBF

Subject to circular causation relations

without ethical induction: 'as is' social state
Simulation of SWBF

subject to circular causation relations with ethical induction: 'ought to be' social state

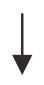

\section{Normative Change}

Mainstream political economy with Axioms of economic rationality, resource scarcity, full-information, competition and conflict:

Marginalist hypothesis

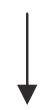

$\longrightarrow$ Episteme of unity of knowledge with the axioms of learning process as exhibited by the Interactive, Integrative and Evolutionary properties: end of scarcity, rise of participatory and sharing political economy

\section{Normative Transformation}

Interpretations of estimated coefficients 'as is': social choices of policy and market states
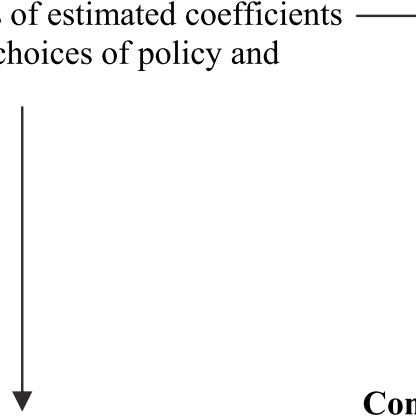

Simulation of estimated coefficients in respect of social choices: policy, institutional and market states with better social states under the episteme of unity of knowledge and sustainability

Determination of simulated social vectors and coefficients

\section{Contrast}

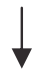

The form of estimated wellbeing function $\leftrightarrow$ The form of simulated wellbeing function

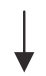

Contrast (SWBF)

Policy-theoretic analysis in the estimated case $\leftrightarrow$ Policy-theoretic analysis in the

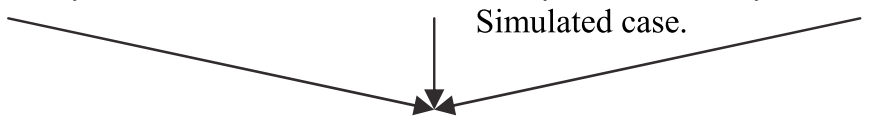

Continue over time and continuum of systems (expanded set of variables and issues)

Fig. 1. Schema of social reconstruction out of estimated leading to simulation 
For further details see the next section. The meaning of social reconstruction is that of normatively recommending structural change, biodiversity, policy diversity, and program developments for sustaining a coexisting, participatory and endogenously knowledgeinduced world-system of possibilities. The result is simulation of social wellbeing towards attaining better states out of the fallen states of marginalism, differentiation and resource paucity that mainstream idea of sustainability otherwise conveys through its constricted models of science, society and economy.

Despite the process-oriented structure of the learning world-system for sustainability, the foundational episteme, theory, dynamics and consequences of our wellbeing simulation subject to circular causation results are opposed to the dialectical process-oriented worldview of mainstream political economy. The dialectical process of the unification dynamics is based on unity of knowledge as the power enabling sustainability. The dialectical process of conflict and power in mainstream science, society and economy studies do not establish a unified world-system. Even the idea of consciousness attained by creative evolution and learning in the framework of unity of knowledge, time and space dimension is opposed to the idea of consciousness and the universe in space-time dimension. The latter form is conveyed by Quantum Physics (Kafatos \& Nadeau, 1990), Relativity Physics (Einstein, trans. Lawson, 1960), and political economy (Wallerstein, 1998).

The following figure shows the template of social reconstruction from 'as- is' to 'as-it-oughtto-be' social state. Further details on the social reconstruction perspective are given in the next section on the construct of the learning-process model of sustainability.

\section{The knowledge-induced formalism of learning process in unity of knowledge as the episteme}

The various characteristics, definitions and explanations of critical terms presented in the preceding sections are now assembled in the following model representation of the learning process of unity of knowledge and the knowledge-induced unified world-system. The precept of unity of knowledge that grounds the entire study of sustainability in its embedded social sense is pervasive in the model shown by expression (2).

Firstly, there is unity at the foundational epistemic origin by way of enunciating the law. This primal stage is denoted by $[\Omega \rightarrow s\{\theta\}] \equiv\{\theta$; given the epistemic law, $(\Omega, S)\}$. The epistemic law denoted by $(\Omega, S)$ defines the conception formed by knowledge-flows that are socially discoursed. Knowledge-flows that set up the conception of the derived worldview are denoted by ordinally assigned $\{\theta\}$-values in the discursive forums of science, society and economy embedding. $S$ is the mapping of the epistemic Law into functional discourse, and onwards into material and cognitive concrescence of reality.

The functional ontology $\mathbf{f}($.$) denoting logical formalism unravels extended unity between$ the knowledge-induced variables pertaining to the problem under study. The knowledgeinduced variables are denoted by $\{\mathbf{x}(\theta)\}$. The networked and participative nature of causality between the knowledge-induced variables is denoted by the vector of relations, $\mathbf{f}(\theta, \mathbf{x}(\theta))$. The bold notations denote vectors.

The limiting value of $\theta$ in the discursive $\{\theta\}$-space is the result of yet another unity process of learning, the critical characteristics of the learning process in unity of knowledge. It comprises the total phase of Interaction, Integration coming together and leading up to the point of creative Evolution to establish sustainability by continuity across continuums of systems. 
Unity of the knowledge-induced world-system with particularity of the problems under investigation is shown by the evaluation of the wellbeing function $\mathrm{W}(\mathbf{x}(\theta))$. Unity between the variables and evaluation of systemic unity of the induced world-system under study is sought at any stage of learning by simulating $W(\mathbf{x}(\theta))$, subject to circular causation relations between the $\mathbf{f}(\theta, \mathbf{x}(\theta)$-relations.

Thus the principle of pervasive complementarities between the variables explained by their interrelations in the circular causation system establishes the measured degree of unity between the variables in the problem under investigation. The principle of pervasive complementarities (hence systemic participation) is an empirical representation of unity of the knowledge-induced cognitive phenomena.

Unity is also shown by the recursive nature of coevolutionary learning processes that carry evolutionary epistemology involving $\left(\theta_{N}, \mathbf{x}_{N}\left(\theta_{N}\right), f\left(\theta_{N}, \mathbf{x}_{N}\left(\theta_{N}\right)\right)\right.$ across new knowledge-flows and their induced forms subscripted by N. Now there come about expanding organic unity (symbiosis) across systemic continuums and continuity of knowledge, time and space dimension.

The formal model of learning process in unity of knowledge and the knowledge-induced world-system is now formalized in expression (2).

$$
\begin{aligned}
& (\Omega, S, \theta):\left[\Omega \rightarrow \rightarrow_{\mathrm{S}}\{\theta\}\right] \rightarrow \mathbf{x}(\theta) \\
& \downarrow(\theta, \mathbf{x}(\theta)) \rightarrow \text { Simulation } \mathrm{W}(\mathbf{x}(\theta)) \rightarrow \text { determination } \rightarrow \text { evolution } \\
& \text { subject to, circular of } \theta \text {-ethical into new } \\
& \text { caudation relations index as the } \theta_{\mathrm{N}} \text {-ethical } \\
& \text { denoted by vector of simulated value i.e.knowledge- } \\
& \text { interrelations of wellbeing flows } \\
& \mathbf{f}(\theta, \mathbf{x}(\theta) \quad \text { and knowledge- } \\
& \text { induced values } \\
& \text { continuity of learning across symbiotic continuums }
\end{aligned}
$$

\section{A brief review of the literature on the process concept of sustainability}

Our interest in this paper being on sustainability as a medium of social reconstruction, we therefore focus our review of the literature on the process modeling of systemic learning. This is a new field of inquiry and properly belongs to the area of systems and cybernetics (Choudhury \& Hossain, 2007, 2010). Though we make a brief coverage of a review of the literature in this field, our focus lies on the Gaia concept of process-oriented change leading to sustainability as an embedding concept of participative worldview (Primavesi, op cit). Along the lines of the Gaia concept of sustainability as embedded participative formalism in science and society, there are the important works of Maturana and Varela (1998), Margulis (1998), Lovelock $(1990,2000)$. These authors have a unique message regarding the symbiosis of our relational existence that is reflected in their version of the microbiological Gaia. The common message is well-expressed as one of physical and relational coexistence contra bloody competition and marginalizing power of the strong over the weak, as per social Darwinism.

The important note in this theory is paid to microcosms that form the large scale universe of macrocosm. It is in this area that the Gaia shares a distinctive commonness with the learning worldview of epistemic unity of knowledge. But the epistemic worldview we propound in 
this paper is not constricted by material limitation as exhibited, explained and delimited by the microbiological phenomenon. The micro-organism of knowledge, mind and matter do continue to play important cohesive roles in defining the social political economy as a world-system embedding of the organic interrelations between science, society and economy. This kind of organic unity in diversity of subsystems also conveys the idea of globalism (and globalization) that we will refer to below. The microcosmic order indeed is at the core of the building blocks that rise accumulatively in emergent hubs of interactively integrated and evolved entities.

There is no macrocosmic order as a system separate from the microcosmic one. There is no microcosmic disaggregating of the macrocosmic order into microcosmic entities. There is no lateral addition of the microcosmic subsystems and their variables into a microcosmic totality. There is only a complex aggregation and organization of coordinated forms from the microcosmic level to the macrocosmic level. Everything borrows such a complex systemic and cybernetic meaning of symbiosis, change, freedom and organization resting on the fundamental episteme of unity of knowledge.

At the present time, a gentle flow of papers is appearing in the systems and cybernetic treatment of complementary learning phenomenon. Despite this intellectual advancement in a new field, it is noted that the concept of complementarism is not understood as organic unity of being through the process of becoming in unity of knowledge.

Prigogine (op cit) formulates the idea of cognitive being and becoming in view of the idea of interrelatedness, as in social phenomenon and biological thermodynamics in the following way: Entropy is the inevitable property of change over time. This causes systems of chemical interaction to become highly unstable. Chemical states can be discerned only with probabilistic laws (Boltzmann's law of thermodynamics). When applied to the theme of sustainability, which involves biological and ecological processes of change, consideration of entropy is of much interest. According to the probabilistic nature of entropy in the process of change over time, sustainability becomes a phenomenon in entropy. Sustainability is thereby never attained except with a degree of probability attached to the states of perturbations around an equilibrium point. In the broader sense of the term such evolutionary equilibrium characterized by perturbations and increasing entropy describes dissipative states of the thermodynamic world. Likewise, there occur probabilistic states of dissipated sustainability in the natural order system. We can extend this explanation to the social and economic world of perturbations and process (Georgescu-Roegen, 1971).

Yet this is not the conclusion of our paper in which the epistemic origin of unity can lead into probabilistically determined evolutionary equilibriums of perturbation, but still a state of reverse-entropy can be gained (Choudhury et al, 1998). The resulting state of sustainability with knowledge-induction is a heightened state of denseness in equilibrium. Hence points are gravitated towards dense equilibrium points. The distanced points of dissipative energy away from the dense equilibrium points are reduced in number. Consequently, there exists a high probability of attaining sustainability around densely gravitated knowledge-induced equilibriums that are evolutionary in nature. This is the case of reverse entropy in accordance with the model of bifurcations in fields that are gravitated towards the densely equilibrium points.

Yet bifurcations occur profusely in such learning fields by virtue of the diversity of states that occur out of interactions. Examples of such states in political economy are risk and production diversifications leading to resource augmentation, investments and production; and thereby enabling ownership and distribution of resources, income and wealth. Consumption too, following product diversification, becomes diversified. All of the above 
consequences taken together, though with bifurcation between possibilities of wellbeing, yield effective sustainability by way of systemic embedding.

The model of knowledge-formation by way of Hegelian type dialectics is process-oriented. Carchedi (1991) presents such a model of dialectics in respect of the Marxian concept of money and goods across stages of social transformation. The resulting Money-CommodityMoney model (MCM), on which Heilbroner (1986) expounds his version of a Marxian dialectical model of the monetarist political economy emulates the dialectical dynamics in it. Money now is seen as a process of financial resource accumulation that arises by recycling a quantity of money back and forth between capital accumulation and interest rates creating intertemporal savings.

The learning model of epistemic unity of knowledge also displays dialectical dynamics (Choudhury, 2009b). But the dialectics is premised on the renewal of knowledge-flows and the induced wellbeing of variables of the unified world-system. Money and output, and thereby production, consumption, ownership and distribution are all together symbolic variables that are unified together by recursive causality between them. Consequently, the MCM model explains the evolutionary dynamics of unification by interrelationship between money and the real economy in the wellbeing function that is simulated subject to the circular causation relations in the variables. Now money as an independent and exogenous economic variable loses its meaning.

Sztompka (1991) presents a dialectical model of social evolution in the learning space of the Marxist type. Yet the human consciousness in this model is derived from the premise of rationalism as the episteme. In this regard Sztompka writes (p. 115) : "Our model is certainly 'anthropocentric'; it is founded on the assumption that the irreducible component of society, its only ultimate ontological substratum, is people. Therefore we cannot but seek the ultimate, primary mover of society in their traits and properties - in brief, in human nature." Consequently, power and conflict become the defining characteristics of the society that Sztompka describes. The case is similar to Carchedi's description of Marxist political economy. The normative implication of such a model is that sustainability remains a failed hope. Such a dismay is expressed emphatically by Heilbroner (1991, p. 20 ) in his following words: "Thus to anticipate the conclusions of our inquiry, the answer to whether we can conceive of the future other than as a continuation of the darkness, cruelty, and disorder of the past seems to me to be no; and to the question of whether worse impends, yes."

In the episteme of unity of knowledge in our paper, the social order is a unified systemic whole. Society is the result of integrative preferences of participating individuals and groups, communities and nations. The integrative preferences arise out of their interactive preferences through the medium of discourse and self-institution-market circular causal interrelationships. Preferences are thereby dynamic, evolutionary and complex in nature, though they are guided into symbiosis by the consciousness of self-organization, institutions, science, society and economy.

In respect of the theme of sustainability and complex aggregation of preferences, Hawley's model (op cit) of human ecology stands out as an example. Ecology is explained as a system of organizations inter-relating the human organizational world-system and the environmental world-system. To this I will add the significant place of markets and institutions, ethics and behavior in the ecological convergence process to its well-definition as a human system and a cybernetic field of study. This is also how Johannessen (1998) presents his idea of organizations as social system in search of a system and cybernetic theory of adaptive behavior. 
Hawley presents the characteristics of his human ecological model as comprising three significant properties. These properties agree with the procedural aspects of the learning model of epistemic unity of knowledge that we propound in this paper.

Firstly, the adaptation stage is one of recognizing diversity of interactions between the members; likewise participating and complementary entities. These can also be taken as formal representations of states by means of mathematical and statistical variables.

The second stage is Hawley's maximum stage of adaptation. In the case of the learningprocess epistemic worldview this stage is signified by integration in the holistic sense, consensus in the social sense, and equilibrium in the scientific sense. There is no optimum in the learning process of continuous simulation of knowledge and its induced possibilities. Only evolutionary equilibriums exist, like Thurow's (1996) punctuated equilibriums and Grandmont's (1989) temporary equilibrium.

Hawley's third stage of human ecology model is resumption of the first two stages by continued development and burst of new information. Subsequently, the renewed capacity for the movement of material artifacts continues.

Hawley ascribes these three stages as the adaptive, growth, and evolutionary stages. When placed in the framework of knowledge-sharing of the epistemic origin, the learning model is in agreement with Hawley's. But Hawley's model is limited to the environmental and social ecological dimensions.

Even with large extant of stochastic variations and uncertainty in the ecological order, either of the biological type -- hence environment and systemic globalism -- or of the type of embedded political economy, hence globalization (Thurow, op cit), the worrisome concern is voiced, as by Maurer (1999, p. 23). On the emergent problem of complexity Maurer writes, "The inability to determine causality ultimately arises from a lack of information about the system being considered". This problem is then associated with Maurer's concern with stochastic largeness of the population size, intensive variability caused by inter-member causality, and uncertainty in the behavior of the population membership.

These large-scale complexity problems are resolved in the case of the empirical description of the epistemic learning model -- at least theoretically. The system of circular causation relations based on evolutionary epistemology configures the evolving system in processes. Processes and the empirical evaluation of causality within time-periods depend on the availability of knowledge and its unifying impact on the ecological members. The limits to this kind of evolutionary and overarching systemic configuration are due to the constraints on the availability of systemically generated information along evolutionary processes, lack of appropriate computer-assisted algorithm, and indeterminacy of formalism for the functional ontology of the system, beyond a discursive approach to qualitative modeling of stochasticity.

\section{Sustainability question in systemic globalism and globalization}

Globalism is the phenomenology of intensively interactive, integrative and evolutionary domains of all forms of systems spanning conceptual ones and entire human experience. Such is also the idea of system ensemble advanced by Hubner (op cit) in respect of his theory based on a criticism of linear understanding of history and science. Is globalism in its systemic, evolutionary and unifying perspective a semblance of postmodern thought that bases it worldview on non-foundationalism? I raise the modern-postmodern contrasting ideal in reference to the IIE perspective explaining globalism by raising the following question (Choudhury, 1999, p. 3): "What is post-modernity in the context of a changing 
world order in respect to its economic, social and scientific dimensions? To answer this question one needs to fathom the complexity of interrelationships among human systems. A perspicuous explanation of such a vast web of systemic interrelationships had hitherto remained unexplained in the methodology of modernism. Post-modernity is a response to this modernist incompleteness. It is seen as a methodological questioning of the individualistic worldview of capitalist economic theory underlying modernity by a processoriented possibility in human experience". Our epistemological explanations in this paper have amply established the direction of post-modernist thought in the framework of the episteme of unity of knowledge and its impact on the unified world-system.

Globalization that is of the capitalist genre is either of the following kinds of interactively aggregated world-system: Either the individual rational preferences, even though of individualized groups, aggregate in the linear way to establish a utilitarian society and economy and the attenuating scientific formalism, or the interactive aggregation of such preferences occur as dialectical evolution of power and hegemony for governance adinfinitum. The episteme of unity of knowledge is absent for a conscious understanding of a relational world-system. This idea of methodological individualism is pervasive in the globalism of science, society and economy, hence in the capitalist political economy of globalization. In the sciences as well, Herman Weyl (2009, p. 202-203) voices his concern regarding the episteme of unity of knowledge: "Being and Knowing, where should we look for unity? I tried to make clear that the shield of Being is broken beyond repair. .... Only on the side of Knowing there may be unity.". The dichotomy of being and becoming remains in this kind of scientific thought.

But globalization if conceptualized, established, and pursued by a globally accepted ethical standard (Commission on Global Governance, 1995) need not be a denigrated human experience. The preferences of interacting participants in unifying globalism remain entrenched in complexity. Globalization is now an experience in globalism with a human face. It is expressed by convergence to the commonly determined ethical goals. International discourse and consensus, paradigmatic shift, and awareness to raise consciousness in and of 'everything' become the determining and sustaining factors of globalization with a human experience (Dunning, 2003). We turn now to one such global experience for the wellbeing of the human race and the ecological entirety spanning intergenerational future.

\section{Climatic sustainability by the discursive model of unity of knowledge: The Copenhagen Summit 2009²}

Copenhagen Summit 2009 is where representatives from 192 nations assembled to conduct UN Climate talks with the objective of achieving a binding document towards saving the planet from climatic problems and the fallouts of climate change. The summit concluded at a document called 'Copenhagen Accord' after seeing sharp differences between rich and poor countries, as also differences amongst the highest polluting nations.

\footnotetext{
2 This section is extracted from Dr. Lubna Sarwath Mohammad's doctoral thesis entitled, "Institutional political economy - Islam and the occident: methodology with a case study of Sultanate of Oman", Faculty of Economics (Islamic economics and finance), Trisakti University, Jakarta, Indonesia. The section applies the methodology of unity of knowledge as explained in this paper to an important example of the institutional case of political economy in global discourse.
} 
What have been portrayed as the positive developments at the summit are fund mobilization from industrialized nations to meet the challenges of climate change for developing countries to the tune of $\$ 100$ billion by the year 2020. This is expected to cope with adverse climate changes, drought and floods. Also a short-term fund of $\$ 30$ billion over 3 years by 2012 has been provided for adapting to climate changes and shifting to clean energy. A method of verification of greenhouse gas emission cuts has been agreed upon. Countries are to list actions taken to cut global warming pollutants by specific amounts. A target has been set to limit average temperature increase to below 2 degrees centigrade.

\begin{tabular}{|c|c|}
\hline Provisions of Accord & Failures \\
\hline $\begin{array}{l}\text { - } \$ 100 \text { billion fund mobilization for } \\
\text { developing nations by 2020; } \\
\text { - } \$ 30 \text { billion short term funds over } 3 \text { years } \\
\text { beginning } 2010 \text { for developing nations; } \\
\text { adopting a method of verification of } \\
\text { green house gas polluter cuts; } \\
\text { target set to contain average global } \\
\text { temperature rise by } 2 \text { degree C; } \\
\text { countries to list actions taken to cut } \\
\text { carbon emissions; } \\
\text { industrialized nations under Kyoto } 1997 \\
\text { to face possible sanctions upon failure to } \\
\text { meet emission-cut targets; }\end{array}$ & 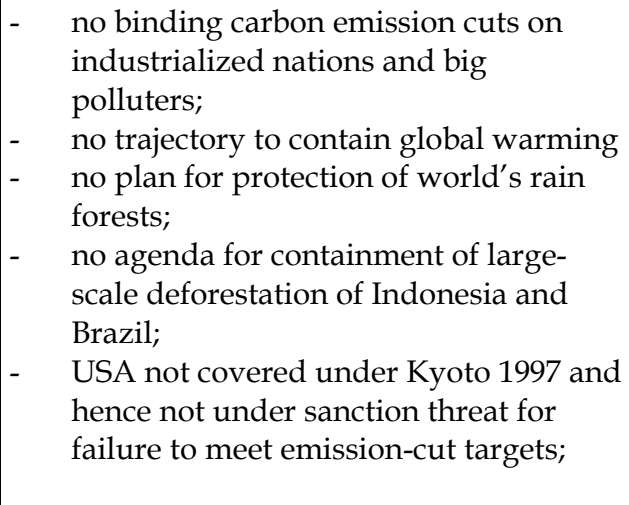 \\
\hline
\end{tabular}

Chart 1. Failures and success of the accord reached at the Copenhagen Summit 2009

The accord though failed to conclude on binding greenhouse gas emission cuts to reach the target of 2 degree centigrade. The agreed upon cuts in July 2009 fall short of avoiding dangerous effects of adverse climate change. Method of verification was the key demand from the USA and was not acceptable to China. Industrialized nations covered under Kyoto Protocol 1997 can face possible sanctions, if failing to meet the emission cuts and the USA is not covered under the Kyoto 1997. No plan has been drafted to protect the world's rain forests vital for healthy climate. There was no payment for 40 poor tropical countries to protect their woodlands. Non-industrial pollution by way of deforestation for logging, cattle-grazing and crops has made Brazil and Indonesia third and fourth largest carbon emitters after China -- and USA was not highlighted.

Having tabled the salient features of the Copenhagen Summit 2009 in terms of failures and the accord contours, we will now examine the functionality of Consultative Participatory interactive, integrative and evolutionary (IIE) learning process by simulating the Copenhagen Summit of December 7-18, 2009 as Copenhagen Consultative Participatory Summit 2009.

The under-mentioned points form the foundation of the psychological setup of an envisioned Copenhagen Consultative Participatory (IIE) discourse:

- Knowledge-building as a learning process is at the core of the IIE-learning process and is conceptualized on a particular pragmatic axiom.

- IIE-learning process admits of 'impossibility of certainty of knowledge'; learning is simulacra of possibilities. 
- There is absoluteness of the epistemic stock of knowledge, viz., unity of knowledge to form the substance or theme of the Summit.

- The vastness of unknown knowledge cannot be fully exhaustible in our worldly learning experience.

- The method of optimality is replaced by evolutionary learning form of simulation of values and realistic targets.

- Transparency, accountability, judicious responsibility and broad-based development as the standard for conduct of decision-making and decision-taking prevail, or are aimed for.

- Realization of unity of knowledge and unity of systems through participatory development, pervasive complementarities, and circular causation organic linkages is the method.

- A degree of unity of systems and knowledge as criteria for wellbeing is evaluated.

- Ensuring wide representation and broad participation for large interactions and consensus for eventual implementation is institutionally necessary.

The participants of our proposed Copenhagen Consultative Participatory Summit would then work with a consciousness that permeates towards realization of the epistemic organic unity in the systems. The theory of political economy of institutionalism does not underestimate the role of psychology in socio-scientific and economic study. These reckon the intention and attitude of shared participation as a component IIE-process variable.

We argue that the natural systems are interacting with the world-systems, even as the natural systems and the world-systems are interacting among themselves as well. These result in intra- and inter- systemic synergies leading to organic symbiosis. Yet, environmental issues and ecological factors have been rendered exogenous at strategic policy designing for economic growth and development in Copenhagen Summit. In the Consultative Participatory type Copenhagen Summit, the entities representing technology, production, geo-political strategies, and capturing of markets are made to mutually interact. The proposed Copenhagen Consultative Participation in this paper would have the in-built IIE-learning process. The knowledge-building proposals in such a Copenhagen Consultative Participatory institution would follow the methodological function of the IIE-recursive learning process. At each round of the discourse, the entities would be interacting with the epistemic premise of unity of knowledge. Under repeated recursive discourses on the serious concerns of climate change, the devastating repercussions are addressed in the light of the complaints of the developing countries and the historical faults of developed nations.

At Copenhagen Consultative Participatory body each round of discourse is having a mechanism to recall the episteme of organic unity. The knowledge deduced and the simulated levels of common wellbeing of the participating entities and the corresponding variables in this regard would go through a circular causation knowledge-gaining process.

The interactive, integrative and evolutionary form of learning in unity of knowledge in our proposed Copenhagen Consultative Participatory institutional model is shown in Figure 2.

\section{Conclusion}

This paper has broken new grounds on the theme of social reconstruction of globalization by examining the epistemological roots of thought, model conceptualization and application underlying the science, society and economy embedding. The theme of social political economy in this epistemic sense was laid down in a synergistic model of embedding 


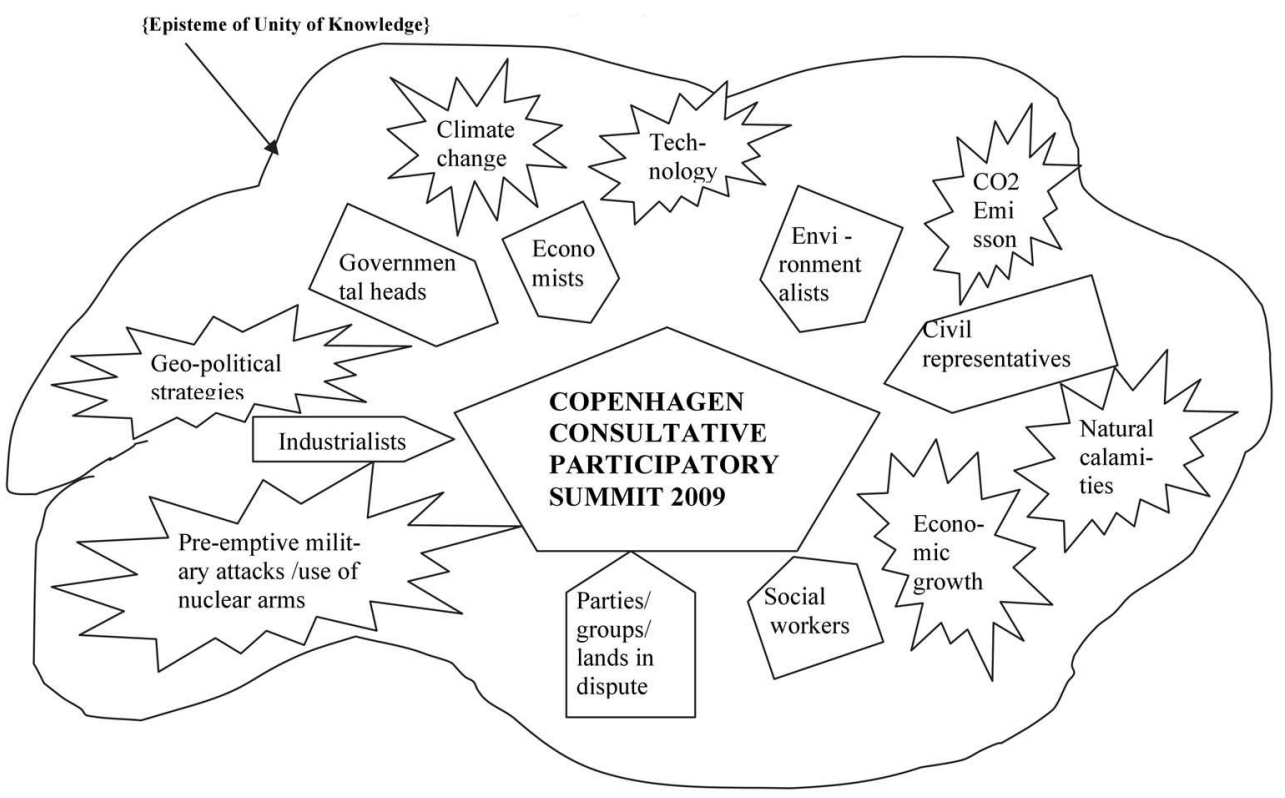

Fig. A representation of the proposed Copenhagen Consultative Participatory Summit 2009

between the interacting, integrative and evolutionary domains of human activities. The substantively new idea of political economy in this social sense was thus established. Such a definition recognizes the traditional one on conflict and power in the ownership, distributional and production of resources. But it extends to the moral and ethical foundation of unity of knowledge and its epistemic influence on the construction of politicoeconomic issues under study. The theme of globalization was thus placed in the midst of this worldview.

The paper also formulated a non-mathematical textual version of a model of extensive participation. The premise of unity of knowledge and its structural representation in the global world-system involving science, society and economics were thus explained. Such a path towards moral and ethical reconstruction of the social question was considered as the way towards a new social contract under globalization with human face.

The application of the model of unity of knowledge and its discursively driven organic participation to the case of the Copenhagen Summit on Climate Change was done. In this way the future model of global political economy with embedded synergy in it was exemplified for political and institutional consideration.

\section{References}

Barbier, E. 1986, "Economic growth: the political economy of resource misallocation", in Ekin, P. ed. The Living Economy, a New Economics in the Making, London, Eng: Routledge and Kegan Paul, pp. 10-12.

Barrow, J.D. 1991, Theories of Everything, the Quest for Ultimate Explanation, Oxford, Eng: Oxford University Press. 
Behrman, J.N. 2003, “Transformation of society: implications for globalization”, in Dunning, J.H. ed. Making Globalization Good, Oxford, UK: Oxford University Press, pp. 108144.

Braudel, F. 1995, A History of Civilizations, New York, NY: Penguin Books.

Campbell, D.T. 1974, "Evolutionary epistemology", in Schilpp, P.A. ed. The Philosophy of Karl Popper, LaSalle: Open Court, pp. 413-463.

Carchedi, G. 1991, Frontiers of Political Economy, New York, NY: Verso.

Choudhury, M.A. 1999, Comparative Economic Theory, Occidental and Islamic Perspectives, Norwell, MA: Kluwer Academic Publishers.

Choudhury, M.A. 2004, The Islamic World-System, a Study in Polity-Market Interaction, London, Eng: RoutledgeCurzon.

Choudhury, M.A. 2007, The Universal Paradigm and the Islamic World-System, Economy, Society, Ethics and Science, Singapore: World Scientific Publication.

Choudhury, M.A. 2009a, "Which of the two? - knowledge or time", Philosophical Papers and Review, 1:1.

Choudhury, M.A. 2009b, "Dialectics in socio-scientific inquiry: Islam contra Occident", International Journal of Sociology and Social Policy, 29:9/10.

Choudhury, M.A. 2011, “Overlapping generation model for Islamic asset valuation: a phenomenological application", Chapter 8 of his Islamic Economics and Finance, an Epistemological Inquiry, West Yorkshire, UK: Emerald Publication.

Choudhury, M.A. M. Shahadat Hossain \& M. Mohiuddin 1998, "Violent effects of deforestation and watershed management on wave and ocean current cybernetical relationships: an empirical study with respect to Bangladesh ecology", Kybernetes: International Journal of Systems and Cybernetics, Vol. 27, No.5.

Choudhury, M.A.\& Hossain, M.S. 2007, Computing Reality, Tokyo, Japan: Blue Ocean Press for Aoishima Research Institute.

Choudhury, M.A.\& Hossain, M.S, 2010, "Neuro-Cybernetics of socio-Scientific systems", Mind and Society, Vol. 9, pp. 59-83.

Choudhury, M.A. \& Zaman, S.I. 2009, “Self-referencing as socio-scientific methodology in contrasting paradigms", Kybernetes, International Journal of Cybernetics, Systems and Management Studies, 38:6.

Committee on Global Governance, 1995, Our Global Neighbourhood, Oxford, UK: Oxford University Press.

Coombs, H.C. 1990, The Return of Scarcity, Cambridge, UK: Cambridge University Press.

Daly, H.E. 1992, "From empty-world to full-world economics: recognizing an historical turning point in economic development", in R. Goodland, H.E. Daly, S. el-Serafy \& B. von Droste Eds. Environmentally Sustainable Economic Development: Building on Brundtland, pp. 29-40, Paris, France: UNESCO.

Darwin, C. 1985 [1859] ed. J.W. Barrow, The Origin of Species by Means of Natural Selection, London, Eng: Penguin.

Dawkins, R. 1976, The Selfish Gene, New York: Oxford University Press.

Descartes, R. 1954, "Discourse on method", in S. Commins \& Linscott, R.N. Eds. Man \& the Universe: The Philosophers of Science, pp. 163-220, New York, NY: Pocket Books, Inc

Dunning, J.H. 2003, “The moral imperatives of global capitalism: an overview", in Dunning, J.H. ed. Making Globalization Good, Oxford, UK: Oxford University Press, pp. 11-40.

Einstein, A. 1960, Relativity, The Special and the General Theory (London, Eng: Methuen. 
Foucault, M. trans. A.M. Sheridan 1972, The Archeology of Knowledge and the Discourse on Language, New York: Harper Torchbooks.

Georgescu-Roegen, N. 1971, The Entropy Law and the Economic Process, Cambridge, MA: Harvard University Press.

Grandmont, J-M. 1989, "Temporary equilibrium”, in Eatwell, J. Milgate, M \& Newman, P. eds. New Palgrave: General Equilibrium, W.W. Norton, New York, NY

Gruber, T.R. 1993. "A translation approach to portable ontologies", Knowledge Acquisition, Vol. 5, No. 2, 199-200.

Hammond, P.J. 1987, "Social choice: the science of the impossible", in Feiwel, J.R. (ed.) Arrow and the Foundations of the Theory of Economic Policy, London, UK: Macmillan Press Ltd. Pp. 116-134.

Hawley, A. 1986, Human Ecology, Chicago, IL: University of Chicago Press.

Heidegger, M. trans. A. Hofstadter, 1988. The Basic Problems of Phenomenology, Bloomington \& Indianapolis, IN: Indiana University Press.

Heilbroner, R.L. 1986, "The ideology of capital", in his The Nature and Logic of Capitalism, Chapter 5, New York, NY: W.W. Norton.

Heilbroner, R.L. 1991. An Inquiry into the Human Prospect, New York, NY: W.W. Norton. Heiskala, 2003

Hubner, K. trans. P.R. Dixon, Jr. \& H.M. Dixon 1985, “Foundations of a universal historistic theory of the empirical sciences", in his Critique of Scientific Reason, pp.105-

122, Chicago, IL: The University of Chicago Press.

Hull, D.L. 1988, Science as a Process, an Evolutionary Account of the Social and Conceptual Development of Science, Chicago, IL: University of Chicago Press.

Inglott, P.S. 1990, "The rights of future generations: some socio-philosophical considerations", in S. Busuttil, E. Agius, P.S. Inglott \& T. Macelli Eds. Our Responsibilities Towards Future Generations, pp. 17-27, Malta: Foundation for International Studies \& UNESCO.

Johannessen, J-A. 1998, “Organizations as social systems: the search for a systemic theory of organizational innovation processes", Kybernetes, the International Journal of Systems and Cybernetics, 27: 4\&5, pp. 359-387.

Kafatos, M. \& Nadeau, R. 1990. "The road untraveled: enlarging the new logical framework of complementarity", in their Conscious Universe, New York, NY: Sringer-Verlag.

Kim, W. C \& Mauborgne, R. 2005, Blue Ocean Strategy, Boston, MA: Harvard Business Press.

Koizumi, T. 1993, Interdependence and Change in the Global System, Lanham, Maryland: University Press of America.

Lovelock, J. 1990, "Gaia and the balance of nature", in Schrift, A.D. (ed.) The Logic of the Gift, London, UK: Routledge.

Lovelock, J. 2000, "Foreword", in Primavesi, A. Sacred Gaia, London, Eng.

Maddox, I.J. 1970, Elements of Functional Analysis, Cambridge, Eng: Cambridge University Press.

Margulis, L. 1998, The Symbiotic Planet, London, UK: Weidenfield and Nicolson.

Martinez-Alier, J. 1987, Ecological Economics: Energy, Environment and Society, Oxford, UK: Basil Blackwell.

Maturana, H.R. and Varela, F.J. 1998, The Tree of Knowledge, Boston, USA: Shambhala.

Maurer, B.A. 1999, "Communities as non-linear systems", in his Untangling Ecological Complexity, Chicago, ILL: The University of Chicago Press. 
Myrdal, G. 1987. "Utilitarianism and modern economics", in Feiwel, G.R. Arrow and the Foundations of the Theory of Economic Policy, London, Eng: Macmillan, pp. 273-278.

Nozick, R. 2001, Invariances, the Structure of the Objective World, Cambridge, MA, USA.

Phelps, E.S. 1989, "Distributive justice”, in J. Eatwell, P. Newman \& M. Milgate eds. New Palgrave: Social Economics, New York, NY: W.W. Norton.

Popper, K. 1988, "Natural selection and the emergence of mind", in G. Radnitzky \& W.W. Bartley, III Eds. Evolutionary Epistemology, Rationality, and the Sociology of Knowledge, pp. 139-54, La Salle, IL: Open Court.

Prigogine, I. 1980. From Being to Becoming, San Francisco, CA: W.H. Freeman.

Primavesi, A. 2000, Sacred Gaia, London, Eng: Routledge.

Quirk, J. and Saposnik, R. 1968, Introduction to General Equilibrium Theory and Welfare Economics, New York, NY: McGraw-Hill Book Co.

Rawls, J. 1971, A Theory of Justice, Cambridge, MA: Harvard University Press.

Romer, P.M. 1986, "Increasing returns and long-run growth", Journal of Political Economy, Vol. 94, pp. 1002-37.

Sarwath, L.M. 2011, Institutional political economy - Islam and the occident: methodology with a case study of Sultanate of Oman, unpublished doctoral thesis, Faculty of Economics (Islamic Economics and Finance), Trisakti University, Jakarta, Indonesia.

Simon, H. 1957, Models of Man, New York, NY: John Wiley \& Sons.

Sklair, L. 2002. "Transnational corporations and capitalist globalization", in Globalization, Capitalism and Its Alternatives, Oxford, Eng: Oxford University Press, pp. 59-83.

South Commission, 1990, The Challenge to the South, Oxford, Eng: Oxford University Press.

Staniland, M. 1985, "The fall and rise of political economy", in What is Political Economy? A Study of Social Theory and Underdevelopment, pp. 10-35, New Haven, CT: Yale University Press, 1985.

Sztompka, P. 1991, Society in Action, the Theory of Social Becoming, Chicago, IL: University of Chicago Press.

Thurow, L.C. 1996, "New games, new rules, new strategies", in his, The Future of Capitalism, London, Eng: Nicholas Brealey Publishing.

Wallerstein, I. 1998, "Spacetime as the basis of knowledge", in O.F. Borda Ed. People's Participation, Challenges Ahead, pp. 43-62, New York: The APEX Press.

Weyl, H. 2009, "The unity of knowledge", in his Mind and Nature, Princeton, NJ: Princeton University Press, pp. 194-203.

Whitehead, A.N. 1978, Process and Reality, D.R. Griffin \& D.W. Sherburne Eds. New York: The Free Press. 


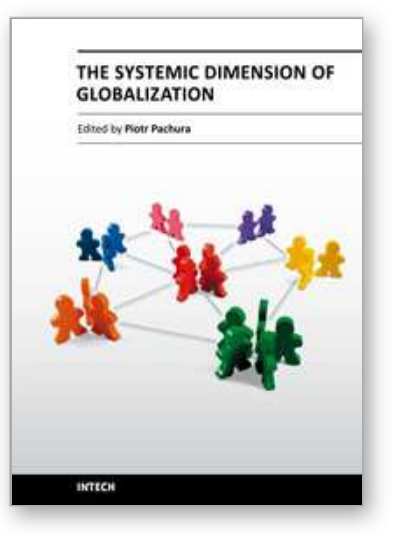

\author{
The Systemic Dimension of Globalization \\ Edited by Prof. Piotr Pachura
}

ISBN 978-953-307-384-2

Hard cover, 288 pages

Publisher InTech

Published online 01, August, 2011

Published in print edition August, 2011

Today science is moving in the direction of synthesis of the achievements of various academic disciplines. The idea to prepare and present to the international academic milieu, a multidimensional approach to globalization phenomenon is an ambitious undertaking. The book The Systemic Dimension of Globalization consists of 14 chapters divided into three sections: Globalization and Complex Systems; Globalization and Social Systems; Globalization and Natural Systems. The Authors of respective chapters represent a great diversity of disciplines and methodological approaches as well as a variety of academic culture. This is the value of this book and this merit will be appreciated by a global community of scholars.

\title{
How to reference
}

In order to correctly reference this scholarly work, feel free to copy and paste the following:

Masudul Alam Choudhury and Lubna Sarwath Mohammad (2011). Sustainability by Interrelating Science, Society and Economy in Embedded Political Economy - an Epistemological Approach, The Systemic Dimension of Globalization, Prof. Piotr Pachura (Ed.), ISBN: 978-953-307-384-2, InTech, Available from: http://www.intechopen.com/books/the-systemic-dimension-of-globalization/sustainability-by-interrelatingscience-society-and-economy-in-embedded-political-economy-an-epistem

\section{INTECH}

open science | open minds

\author{
InTech Europe \\ University Campus STeP Ri \\ Slavka Krautzeka 83/A \\ 51000 Rijeka, Croatia \\ Phone: +385 (51) 770447 \\ Fax: +385 (51) 686166 \\ www.intechopen.com
}

\author{
InTech China \\ Unit 405, Office Block, Hotel Equatorial Shanghai \\ No.65, Yan An Road (West), Shanghai, 200040, China \\ 中国上海市延安西路65号上海国际贵都大饭店办公楼 405 单元 \\ Phone: +86-21-62489820 \\ Fax: +86-21-62489821
}


(C) 2011 The Author(s). Licensee IntechOpen. This chapter is distributed under the terms of the Creative Commons Attribution-NonCommercialShareAlike-3.0 License, which permits use, distribution and reproduction for non-commercial purposes, provided the original is properly cited and derivative works building on this content are distributed under the same license. 